\title{
Foreign Inclusions, Enclosed Cavities, Partial Discharge Models and Discharge Energy: A Short Review Regarding Solid Dielectrics and Composite Insulating Systems
}

\author{
M. G. Danikas \\ Democritus University of Thrace \\ Department of Electrical and Computer Engineering \\ Power Systems Laboratory \\ Xanthi, Greece \\ mdanikas@ee.duth.gr
}

\author{
S. Morsalin \\ University of New South Wales \\ School of Electrical Engineering and Telecommunications \\ High Voltage Laboratory \\ Sydney, Australia \\ sayidul.morsalin@unsw.edu.au
}

\begin{abstract}
Partial discharges in cavities are one of the main reasons of breakdown of insulating materials and insulating systems in general. The present paper aims at commenting some aspects of the relation between partial discharges and insulation damage. Some basic models explaining the workings and impacts of discharges in cavities are discussed. Discussions about the possibility of damage in the presence of multiple cavities as well as of the risks of minute discharges and/or charging phenomena below the so-called inception voltage are conducted. It is remarked that the question of the relationship between discharge parameters and insulation damage is still an important one, especially for composite insulating systems.
\end{abstract}

Keywords-solid dielectrics; partial discharges; inception voltage; insulation damage; discharge magnitude; discharge energy; charging phenomena

\section{INTRODUCTION}

Partial discharge is the name given to an electrical discharge, which involves only a portion of the dielectric without fully bridging the electrodes [1]. Partial discharges often happen in enclosed cavities of insulation and thus they are sometimes called internal partial discharges. They can be extremely harmful to solid insulating materials and they start appearing when a cavity is subjected to an AC stress greater than its breakdown value. They may occur regularly at each half period of an applied sinusoidal voltage [2]. Partial discharges in a dielectric develop in enclosed cavities (or because of inclusions) of lower dielectric strength than the dielectric strength of the surrounding material. The insulation in the inclusion breaks down at a stress lower than the dielectric strength of the surrounding material. The voltage at which discharges start occurring regularly in an enclosed cavity is called inception voltage [3]. When the voltage is reduced under a certain limit, discharges stop occurring. This limit is thus called extinction voltage [3] (all the above under the assumption that $\mathrm{AC}$ voltage is applied). Enclosed cavities may be found in extruded plastics, lapped impregnated paper and cast resins, they may be filled with oil (as in layers and in butt gaps of oil-impregnated paper insulation) or may consist - as inclusions - of various foreign particles (like textile fibers or dirt). It is the aim of the present paper to give a review regarding the problems arising because of partial discharges and their injurious effects on the insulating materials. However, the present paper is by no means an exhaustive review of all of the aspects of partial discharges and their deleterious effects.

\section{PARTIAL DISCHARGE MODELS}

Partial discharges in enclosed cavities may be represented with the well known a-b-c model (or capacitor model) $[4,5]$. This model is based on the assumption that the enclosed cavity may be represented as capacitance, while the neighboring to the cavity healthy insulation may be represented by another capacitance and yet another capacitance may represent the rest of the insulating material. In such a case, the apparent charge Q detected by a PD detector may be given as:

$$
\mathrm{Q}=\mathrm{C}_{\mathrm{b}} \cdot \Delta \mathrm{V}_{\mathrm{c}}
$$

where, $\mathrm{C}_{\mathrm{b}}$ is the capacitance of the healthy insulation adjacent to the cavity and $\Delta \mathrm{V}_{\mathrm{c}}$ the voltage change that is caused because of the discharge inside the cavity. This quantity, although not determined by the dimensions of the cavity alone, as $\mathrm{C}_{\mathrm{b}}$ is affected by the insulation thickness, is considered approximately a right measure of a discharge [6]. Related to the abc model is also the energy of an individual discharge, which is given as:

$$
\mathrm{W}=0.7 \cdot \mathrm{Q} \cdot \mathrm{V}_{\mathrm{i}}
$$

where, $\mathrm{Q}$ is the apparent charge of an individual discharge and $\mathrm{V}_{\mathrm{i}}$ the discharge inception voltage [6].

Such a model, although very useful for many decades, was subjected to criticism [7], where it was opined that the notion of capacitance is limited to metal electrodes and not to insulating surfaces facing each other. Thus, another model was 
proposed, named Pedersen's model [7], based on electromagnetic theory:

$$
\mathrm{Q}=\mathrm{k} \cdot \Omega \cdot \varepsilon_{\mathrm{r}} \cdot \varepsilon_{0} \cdot\left(\mathrm{E}_{\mathrm{i}}-\mathrm{E}_{\mathrm{l}}\right) \nabla \lambda_{0}
$$

where, $\mathrm{Q}$ is the charge induced on the measuring electrode by the partial discharge in a cavity, $\mathrm{k}$ the cavity geometric factor, $\Omega$ the cavity volume, $E_{\mathrm{i}}$ the inception electric field for streamer inception, $\mathrm{E}_{1}$ the limiting electric field for ionization, $\varepsilon_{\mathrm{r}}$ the relative permittivity of the surrounding solid insulating material, $\varepsilon_{0}$ the permittivity of the free space and $\nabla \lambda_{0}$ the function which gives the ratio of the electric field at the position of the cavity (in the absence of the cavity) to the voltage between the electrodes. The quantity $\left(\mathrm{E}_{\mathrm{i}}-\mathrm{E}_{\mathrm{l}}\right)$ is calculated in terms of the streamer criterion, i.e.:

$$
\left(E_{i} / p\right)=(1+B / \sqrt{2} \cdot a \cdot p) E_{1} / p
$$

where, $\mathrm{B}$ is a constant characteristic for the gas in the cavity, a the radius of the cavity and $p$ the pressure in the cavity. As discussed in [8], the merit of (3) is that the charge Q is related to a variety of parameters. This model was referring to streamer type discharges. Such a model was preceded by the model proposed in [9]. According to that model, the apparent charge $\mathrm{Q}$ is given from the following equation:

$$
\mathrm{Q}=\varepsilon_{\mathrm{r}} \cdot \varepsilon_{0} \cdot \mathrm{E}_{2} \cdot \gamma \cdot \mathrm{V} / 1_{\mathrm{a}}
$$

where $\varepsilon_{\mathrm{r}}$ and $\varepsilon_{0}$ as in (3), $\mathrm{V}$ is the volume of the cavity, $\gamma$ is the $\lambda_{0}, E_{2}$ is the partial discharge inception voltage according to Paschen's law and $l_{\mathrm{a}}$ the geometry factor depending on the axis ratio of the cavity. It is evident from (5) that this model refers mainly to Townsend type of discharges (since it considers the partial discharge inception stress from Paschen's law viewpoint). In actual fact, the models of [7] and [9] have a number of common parameters.

Criticism of Pedersen's model came from [8, 10], where it was pointed out that Pedersen's model is valid for initial experimental conditions and that (3), which is vital to the model, assumes a breakdown in a uniform gap (cavity breakdown, however, is not, strictly speaking breakdown, but it leads to redistribution of charges on the surface of the cavity). Subsequent criticism came from [11], where it was indicated that a direct correlation between the space charges and the change of capacitance exists and that the criticism against the change of the capacitance of the system in relation to space charges has been opposed by utilizing Pedersen's equations. However, it must be mentioned that -as far as some experimental results with enclosed cavities in polymers are concerned- Pedersen's model fared quite well (in comparison to the capacitor model) and gave closer theoretical discharge values to the experimental ones [12-14]. On the other hand, one should point out that in these experiments [12-14], only partial discharges under initial experimental conditions were investigated.

\section{CONSEQUENCES OF PARTIAL DISCHARGES}

Quite early, there were experiments with plane discs from clean polyethylene having small cylindrical cavities and a uniform electrode arrangement [15]. The author of [15] calculated that about $10-15 \mathrm{~cm}^{3}$ of polyethylene was eroded by each discharge having a magnitude of $10 \mathrm{pC}$. The deterioration was dramatically increased if the applied voltage was raised above the inception voltage. In yet another work [16], the same researcher pointed out that among the main factors affecting the rate of deterioration of an insulating material are the ratio of the applied voltage to the discharge inception voltage, the magnitude and energy of the discharges, the waveform and frequency of the applied voltage, the resistance of the material both to the discharge erosion and to chemical attack by the byproducts generated by the discharge and finally the electrical and chemical characteristics of the ambient medium. (resonance of the work - mentioned in $[15,16]$ - on the effect of the waveform of the applied voltage can be found in [17] and also in a more recent work [18], where there was an investigation on partial discharges in rotating machine insulation). The energy of discharges affects the local temperature rise at the point of impact of the discharges, and subsequently the value of the local dielectric strength is attained [19]. Differences in discharge characteristics and time to breakdown arise if the cavity is (a) sealed or ventilated, and (b) surrounded by the insulation or adjacent to a conductor. Moreover, conditions of pressure and temperature used during the processing of polymers (molding, curing) may greatly affect their "molecular packing" and consequently their resistance to discharge channels [20].

Investigation of the behavior of discharges in air gaps facing solid insulation indicated that an increase of discharge magnitude with increasing voltage, which was explained in terms of a continuous recombination and neutralization of deposited surface charges which will reduce the shielding effect [21]. Such a phenomenon will keep the discharge going and will cause a fresh and greater generation of surface charge. Testing artificial and natural cavities in insulating materials (polyethylene and polyethylene terephthalate), the author of [22] found that the inception voltage of natural cavities formed in polyethylene was two to four times the calculated inception voltage, assuming that the electric field is uniform in the cavity. Oxalic acid crystals and water vapor, when present in the cavity, are factors of serious deterioration of the material. Confirmation of the above can be seen in [23], where it was stated that chemical byproducts contribute to charge deposition on the cavity inner walls and, thus, to the modification of discharge magnitudes in subsequent discharges.

Internal cavities with discharges cause lesser damage compared to cavities undergoing discharges, which are adjacent to electrodes [24]. This has been observed also in [15]. Discharges in cavities with a large diameter/depth ratio cannot extinguish as in cavities with a small diameter/depth ratio. The former type of cavity is likely to have the more injurious effect on the insulation. In [23], it was reported that for very small cavities, the inception voltage decreases as the cavity depth increases, following the Paschen curve of breakdown, thus agreeing with [24]. The increase of the number of discharges per unit time with frequency, the increase of the number of discharges with increasing electric stress in the dielectric, the increase discharge magnitude with increasing depth of the cavity as well as with its area, all these were observed experimentally in [6]. Recent research indicated that, although an increase in cavity diameter causes more discharges of large 
magnitude, an increase in cavity depth causes an increase in inception voltage [25]. This conclusion is at variance with [23].

The authors of [26], working with a non-uniform electrode system and polyethylene samples, observed that the main chemical change occurring in polyethylene when exposed to discharge activity are crosslinking, increase in unsaturation and hydrogen evolution. The rate of chemical change depends on the total discharge energy and concentration of end products. The total volume of hydrogen $\mathrm{V}$ (in $\mathrm{ml}$ ) in a system at a time of t seconds is empirically given by:

$$
\mathrm{V}=\sqrt{2} \cdot \mathrm{K} \cdot \mathrm{t}
$$

where, $\mathrm{K}$ is the hydrogen evolution coefficient which is directly proportional to the total discharge energy per cycle. Furthermore, in [26] it was pointed out that semiconducting surface films play a significant role in retarding the ultimate failure of the insulation, agreeing in this respect with [6].

The discharge rate rises almost linearly with the applied voltage irrespective of the gap setting and vapor pressure in a spark gap [27]. It was also reported that the discharge process in artificial cavities is more constant than that in natural cavities. The relation between discharge energy and insulation damage is a subject which was and is a vital one for the insulation community. In [28], it was thought preferable to measure continuously both discharge magnitudes and repetition rates in order to better correlate discharge damage with discharge activity rather than measure either the maximum discharge magnitude or the total discharge energy. Later research by the same author [29] confirmed the above conclusions with a variety of insulating materials, such as epoxy resin, polyethylene and mica under AC conditions.

Research in internal discharges in artificial cavities in polyethylene [30], reported that discharges generally decrease in magnitude and repetition rate with time and that absorbed water can greatly influence the pattern of discharges. The decrease of repetition rate of discharges with time happens because of a voltage decrease on the side wall due to the decline of the side wall resistance in the cylindrical cavity. The apparent charge of maximum discharge $\left(\mathrm{Q}_{\mathrm{a}}\right)$ in a cylindrical cavity is given by

$$
\mathrm{Q}_{\mathrm{a}}=\varepsilon_{0} \cdot \varepsilon^{*} \cdot\left(\mathrm{V}_{\mathrm{GO}} \cdot \mathrm{S}\right) /(\mathrm{D}-\mathrm{d})
$$

where, $\varepsilon^{*}$ is the specific dielectric constant of the material, $\mathrm{D}$ is the thickness of the whole specimen and $\mathrm{d}$ the cavity depth, $\mathrm{S}$ being the area of the cavity and $\mathrm{V}_{\mathrm{GO}}$ the inception voltage of the cavity. $\mathrm{Q}_{\mathrm{a}}$ decreases with time because the discharging area is narrowed by the development of low resistance to inner top and bottom surfaces. On the same line of research, it was reported that the impulse inception stress increases with decreasing cavity diameter at constant cavity depth as well as with decreasing depth at constant diameter [31]. The inner workings of discharges in enclosed cavities were the questions tackled in [32], where it was observed that the nature of internal discharges is greatly affected by the assembly of the electrode system and the adhesion of the films and that such discharges become unstable with time, resulting thus in extremely long lifetimes. Such observations were confirmed in [33], where it was reported that the internal surface of the cavity is subjected to physical damage or erosion, or a change in surface electrical resistivity. Pressure change may also occur, again affecting internal discharge activity. Such factors are responsible for the apparent characteristics of discharges in cavities, i.e. their intermittency, cessation and resumption. Furthermore, in [34] it was pointed out by the same authors that gas pressure plays a determining role for internal discharges and, moreover, the question of multiple cavities formed by thermal expansion in extruded cables was discussed.

Experimenting with different arrangements and liquid nitrogen impregnated taped cable insulation, some researchers [35] postulating that discharges occur within bubbles and indicated that the logarithm of the discharge magnitude increases linearly with stress. They proposed that the applied voltage $\mathrm{V}_{\mathrm{a}}$, the inception voltage $\mathrm{V}_{\mathrm{i}}, \mathrm{M}$ the discharge magnitude and $\mathrm{K}$ a constant, are related through the following equation:

$$
\mathrm{V}_{\mathrm{a}}=\mathrm{V}_{\mathrm{i}}+\mathrm{K} \cdot \ln \mathrm{M}
$$

Performing similar experiments, the authors of [36] indicated that the discharge inception voltage depends on the product of butt gap depth and helium density. Discharges start from a point in a butt gap. The probability of the presence of such a point depends on the gap area. In yet another study with pressboard/oil insulation [37], it was shown that, whereas an increase in the magnitudes of discharges by increasing the applied voltage is possible, a decrease of discharge magnitudes is also possible owing to the volume of discharges taking place in gas bubbles in such an arrangement. Discharges start always in the electrically weaker medium, agreeing in this respect with [36]. Moreover, deterioration of the surface of the pressboard is in most cases a necessary condition in order that dangerous discharges will appear in its volume causing thus ultimate failure.

The dependence of discharge inception voltage both on pressure inside the cavity and on cavity diameter was noted in [38]. In fact, it was noted that the discharge inception voltage decreased at low pressures and with increasing cavity diameter, whereas the extinction voltage depends on the conditions of charges trapped on the surface of the dielectric. Similar observations were made some years later [39]. In [39], it was also reported that, under the assumption that the insulation is subjected to combined electrical and thermal stresses, a large cavity gas pressure reduction rate is accompanied by a short time-to-breakdown, whereas a small pressure reduction rate is typical for long times-to-breakdown. In other words, the cavity gas pressure does reflect the ageing rate of polymer specimens. Some researchers noted also a dependence of both inception and extinction voltages on pressure [40]. Electrode design and material processing play also a deciding role according to [40], something also noticed in [32].

A direct relationship between discharge intensity and the rate at which deterioration is taking place in an enclosed cavity was noted in [41]. This relationship was confirmed in yet another study by the same author [42], where it was also observed that discharges initially of large magnitudes decrease with time. Such conclusions were in agreement with [43], that 
suggested that the area associated with each discharge decreases with time and this can happen if the discharges occur between sites where degradation products accumulate. As the degradation products spread over the surface of the cavity, smaller areas between them are available to discharges. Further confirmation of the above was given in [44], where it was reported that the cavity area affected by a discharge is usually much smaller than the area of the whole cavity in which it occurs, and consequently the discharge site is not uniformly discharged.

A study of gaseous degradation products of corona exposed low density polyethylene showed that two degenerative processes were in action [45]: a) crosslinking of polyethylene which may be due to ultraviolet radiation and electrons, crosslinking being evidenced by hydrogen evolution, and b) erosion of polyethylene, which may be due to ion bombardment resulting in organic gases being evolved (CO, $\mathrm{CO} 2, \mathrm{CH} 4)$. Higher temperatures evolve smaller amounts of organic gases since at higher temperatures molecules can dissipate more of the mechanical energy through segmental motion rather than by means of bond breaking processes (e.g. erosion). In [46], the effect of polarity for cylindrical cavities is remarkable only when the applied voltage is equal to the inception voltage, otherwise, as the applied voltage becomes three or four times larger than the inception voltage, the polarity effect almost disappears. This can be explained as at higher voltages, important secondary phenomena, such as photoionization and dissociation of negative ions formed by the preceding discharges, originate from the gas phase and not from the metal electrodes.

The subject of the relation between discharge energy and insulation damage was treated in [47]. The authors found a relationship between the loss of weight and the dissipated power of discharges. They rejected the notion of the importance of isolated discharges and their relation with insulation damage. Their work was in agreement with $[29,48]$. In [49], discharge magnitudes were shown to decrease with the thickness of cavity, whereas they tend to increase with the cavity diameter. The experimental data of [49] are in accordance with those published in [24] but they were at variance with those published in [6]. An approach similar to the one adopted in [47] was also adopted in [50, 51], where, investigating a complex insulation system (consisted of Uniaxially Orientated Polyethylene Tapes (UOPE) and Doecylbenzene oil, the total discharge energy was correlated quite well with the surface area damage of the UOPE tapes (in fact the correlation coefficient between the aforementioned two quantities was in the region of 0.71-0.97, which is considered to be quite satisfactory). It is true, however, that, in such complex insulating systems, besides the surface area damage in the aforementioned work, other deteriorating mechanisms may take place, such as evolution of gases [52]. Moreover, different types of discharges may cause increase or decrease of the gaseous evolution [52]. A more recent publication [53], is in accordance with [52] (albeit using a different electrode arrangement and different insulating materials), pointing out that three types of internal discharges are identified during ageing tests, namely, the first stage of discharges is linked to the streamer-type, the second stage to the Townsend-type and the third stage to the swarming pulsive micro-discharges (SPMD).

The questions of sample thickness, cavity size and partial discharges were treated in [54]. It was shown that with larger specimens, the probability of having bigger cavities increases, and hence a longer free path for the ionization products. Thicker specimens have normally higher discharge activity than thinner ones, for the same value of applied electric field. Relevant to the above, and confirming [54], is work performed some years earlier, where it was reported that thicker insulation needs more sensitive discharge detection equipment. Moreover, the latter conclusion is valid independently of the sort of the enclosed cavity in the insulation, and independently of the discharge model used for the interpretation of the discharge events inside the cavity $[55,56]$. Deteriorating results because of discharge activity in enclosed cavities were noted in [57], where it was reported that the rate of deterioration increases with an increase in concentration of discharges. Deep erosion may ensue with an instability in the dielectric-gas interface. Such a phenomenon may have as a result subsequent discharges to the same site. The observations of [57] were confirmed in a very recent paper [58]. Further confirmation of the above was offered in [59], where the authors carried out a micro-analysis of chemical byproducts regarding the local erosion in enclosed cavities. Localized spots are determined by their chemical byproducts. Oxidative degradation mechanisms are at work and as such they change the discharge patterns.

Important observations regarding the creation of cavities from enclosed conductive contaminants were given in [60]. The authors postulated that high electric stresses develop at the tip of such contaminants and therefore high-energy electrons are injected into the bulk at the negative polarity and trapped electrons are extracted towards the tip at the positive polarity. Such a phenomenon, when repeated in each cycle of the AC voltage, causes a small degraded area at the tip of the contaminant and with the passage of time may render a cavity, which finally may lead to deterioration paths. It should be noted that the ideas about the injection and extraction of charge carriers in [60] could also be seen in earlier publications [30, $33,34]$. Elaborating on the internal discharges, yet another researcher dealt with their two main mechanisms, namely Townsend-like discharges and streamer-like discharges [61]. His research indicated that active species from one half cycle can generate initiating electrons on the next, in accordance with [30, 33-34].

The deteriorating effects of discharges depend on the insulating materials, as shown in [62], where it was observed that discharge activity may lead to depolymerization of silicone rubbers. Indeed, discharge activity in RTV silicone rubber affected the propensity of macromolecular chains to crystallize at very low temperatures more than in HTV silicone rubber. A relatively recent paper [63] indicated the relationship between applied voltage and discharge intensity and also the relationship between discharge intensity and discharge energy. The discharge energy increases almost linearly with discharge intensity, with the authors noting that even a small discharge whose magnitude is $15 \mathrm{pC}$, at an inception voltage of $0.8 \mathrm{kV}$, will release energy of $8.48 \times 10-9$ joules. There was, however, 
no relationship given between discharge energy and insulation damage.

The relationship between cavity diameter and discharge magnitude for enclosed cavities was discussed in some recent publications [64, 65]. Both of them indicated an increase of partial discharge magnitude with cavity diameter and also a decrease of discharge inception voltage with cavity diameter. Such results, albeit with different insulating materials, were in agreement with previous work [24]. The series resistance in the HV circuit has as task to limit the current in the transformer secondary between the HV transformer and the test cell, especially when we are concerned with laboratory experiments. As was noted in [66], the resistance is usually calculated by considering the maximum voltage available and the maximum current allowed. This on one hand has as a result to limit the damage in case of breakdown, but on the other hand the choice of the series resistance also affects the partial discharge activity. The series resistance is an important parameter in determining the current flowing through the test cell as well as the waveforms induced on the test cell's terminals. Since the discharge magnitude or current induced at the terminals is dependent on the current flowing through the HV side, it follows that a smaller current on the HV side will result in a decrease of the individual discharge current pulses.

\section{PARTIAL DISCHARGES AND MULTIPLE CAVITIES}

From the above -non exhaustive- review, it is evident that there is a number of factors affecting the discharge behavior inside enclosed cavities and, consequently, the insulation damage. It is also evident that -especially for laboratory experiments- numerous researchers are confined in the study of only one well defined enclosed cavity. This is logical since the primary aim is to understand the discharge activity in one cavity before one proceeds to the study of more complex insulating systems. In real life, however, multiple cavities may be present. Earlier research in this direction revealed that in the case of adjacent enclosed cavities in an insulating sample, a triggering mechanism may be at work, i.e. an eventual breakdown in one cavity may trigger breakdown in a second one, and so on [67, 68]. As was noted earlier [69-71], although the waveform of the recorded discharge pulses may not differ greatly between an isolated cavity and two (or three) adjacent cavities, the apparent charge recorded is different. This precisely may suggest that a triggering mechanism may be at work.

\section{INFLUENCE OF VERY SMALL PARTIAL DISCHARGES}

Very small discharges may damage an insulation, as suggested earlier in [29] and also in [50, 51], where it was pointed out that such discharges may have a cumulative effect, which with time will produce more material degradation (polymer disruption, carbonization, release of gaseous byproducts etc.). Such views were contested however in [6]. Pioneering work done in [72] revealed that chemical changes observed in an antioxidant free high molecular weight polyethylene (AOFHMW-PE) in cavities above inception voltage were very similar to those obtained with values of applied voltage below inception. In fact, it was found that the presence of byproducts on the surface of similar nitrogen species only when corona and sub-corona took place indicates that corona aging and sub-corona aging result in similar aging products. Since corona currents and resulting species lead to failure of polymer insulations in relatively short times, their findings bore strong evidence that sub-corona aging could lead to serious damage as well, even though a conventional partial discharge detector could not detect any activity. Subsequent work [13-14, 73-74] tends to confirm [72]. Very small partial discharges and/or charging phenomena below inception voltage were observed not only in conventional polymers but also with polymer nanocomposites, albeit with lesser frequency $[75,76]$. Earlier research pointed out the importance of small partial discharges and their influence on possible damaging effects on solid insulation [77-82]. Certainly, the question of the effect of very small partial discharges on insulation degradation is a complex one since it has to do with not only the means of discharge detection and their respective sensitivities but also with the exact terminologies of the various regimes of discharges. Moreover, there is always the question of the thickness of the investigated insulation, the size of minute enclosed cavities as well as the limitations of the discharge detector available, as was noted before [55-56, 83-84].

It is without any doubt that the points raised in [72] merits more attention and research. It must, however, pointed out that, although there are indications that minute discharges (possibly undetected from conventional discharge equipment) and charging phenomena below inception voltage may exist, more work has to be performed with a variety of insulating materials before any definite conclusions can be reached.

\section{FURTHER COMMENTS ON INSULATION DAMAGE}

As noted in [23], the observable effects of partial discharges can be an increase in the loss component of the charging current taken by the capacitive sample, an increased dielectric power loss, radiation of energy in the form of sound, light or ultraviolet radiation, changes in pressure and chemical changes in the dielectric material. Of these effects, the most important -regarding the relation of discharge energy to the material damage- is the last one, i.e. the chemical changes. However, such changes can manifest themselves in different ways, especially if the insulation is a composite one. If, for example, we have a composite insulation of solid/liquid, chemical changes can be gaseous byproducts, changes on the surface of the solid insulation, changes in the liquid itself. Which one of these changes can be related to the discharge energy, or for that matter to any discharge parameter? Any of them or all of them? Such questions are in need of an answer. Although there have been numerous publications on condition monitoring of insulating systems [85-88], there are relatively fewer papers on the actual relationship between discharge energy and material damage. This does not mean that such a relationship does not present some difficulties, especially with composite solid/liquid insulation, as was noted in older publications [89, 90]. In [89], for example, the authors failed to obtain a quantitative relationship between the partial discharge parameters and the gaseous byproducts at atmospheric pressure, explaining that in the course of a test, absorption and evolution of gases were not related to each other with a permanent relationship. It is, however, a better and more reasonable approach, than to try to 
correlate insulation damage with individual discharges, no matter how large their magnitudes are. Recent efforts, however, indicated that for different equipment with defects of the same type, the percentage of gases has similar values. The development of defects in high voltage equipment is accompanied not only by the growth of gas concentrations but also stabilization of the percentage of contents of gases at strictly defined levels. This gives some hope regarding the use of the gas content of oils as an additional criterion for interpreting the results of analysis of gases dissolved in oil and thus to try to correlate them with discharge energy [91]. In this respect, important work performed relatively recently should be taken into account [92-94].

It is true that in the context of the present paper, particular attention was given to the total partial discharge energy. This is not only in agreement with earlier publications [29, 47] but also in accordance with much older ones [95], where it was suggested that the energy dissipation of the individual discharge in an enclosed cavity appears to be more important than the discharge magnitude and the significance of cumulative energy dissipation was stressed.

\section{CONCLUSIONS}

Partial discharges in enclosed cavities consist a major danger for insulating materials. Past research indicated that it is better to try to correlate discharge energy with insulation damage rather than individual discharge magnitudes with insulation damage. The role of sample thickness, the role of cavity dimensions, the role of series resistance in the HV circuit, the role of multiple cavities in the same insulation as well as the possible damaging role of small discharges and/or charging phenomena below inception voltage are reviewed. However, it should be noted that the notion of insulation damage is still an elusive one, especially if we consider composite insulating systems.

\section{RREFERENCES}

[1] N. B. Timpe, "Partial discharge measurements in distributed parameter systems: cables", Engineering Dielectrics, Vol. I: Corona Measurements and Interpretation, ASTM Special Technical Publication, pp. 134-175, 1979

[2] R. Bartnikas, "Corona discharge processes in voids", Engineering Dielectrics, Vol. I: Corona Measurements andInterpretation, ASTM Special Technical Publication, pp. 22-67, 1979

[3] A. Kelen, "Studies on partial discharges on solid dielectrics: A contribution to the discharge resistance testing of insulating materials", Acta Polytechnica Scandinavica, No. EI 16, pp. 138, 1967

[4] A. Gemant, "Die Verlustkurve Lufthaeltiger Isolierstoffe", Zeitscchrift der Technischen Physik, Vol. 13, pp. 184-189, 1932

[5] A. Gemant, W. von Philippoff, "Die Funkenstrecke mit Vorkodensator", Zeitscchrift der Technischen Physik, Vol. 13, pp. 425-430, 1932

[6] F. H. Kreuger, Discharge detection in high voltage equipment, Heywood, London, United Kingdom, 1964

[7] G. C. Crichton, P. W. Karlsson, A. Pedersen, "Partial discharges in ellipsoidal and spheroidal voids", IEEE Transactions on Electrical Insulation, Vol. 24, No. 2, pp. 335-342, 1989

[8] M. G. Danikas, G. E. Vardakis, “The case of Pedersen's theory to model partial discharges in cavities enclosed in solid insulation: A criticism of some of its aspects from an electrical engineers' and from a physicists' point of view", Journal of Electrical Engineering, Vol. 52, No. 5-6, pp. 166-170, 2001
[9] H. Repp, K. W. Nissen, P. Roehl, "Partial discharges in voids: inception conditions and detection limits", Siemens Forschung und Entwicklung Bericht, Vol. 12, pp. 101-106, 1983

[10] M. G. Danikas, I. W. McAllister, G. C. Crichton, A. Pedersen, "Discussion: partial discharges in ellipsoidal and spheroidal voids", IEEE Transactions on Electrical Insulation, Vol. 26, pp. 537-539, 1991

[11] Z. Achillides, M. G. Danikas, E. Kyriakides, "Partial discharge modeling and induced charge concept: Comments and criticism of Pedersen's model and associated measured transients", IEEE Transactions on Dielectrics and Electrical Insulation, Vol. 24, No. 2, pp. 1118-1122, 2017

[12] M. G. Danikas, "Discharge studies in solid insulation voids", CEIDP Conference on Electrical Insulation and Dielectric Phenomena, USA, October 28-31, 1990

[13] M. G. Danikas, A. M. Bruning, "Comparison of several theoretical subcorona to corona transition relations with recent experimental results", IEEE International Symposium on Electrical Insulation, USA, June 7-10, 1992

[14] A. M. Bruning, M. G. Danikas, "Report on continuing work on parallel and non-parallel electric field chemical aging of polymer cavities", 4th International Conference on Conduction and Breakdown in Solid Dielectrics, Italy, June 22-25, 1992

[15] J. H. Mason, "The deterioration and breakdown of dielectrics resulting from internal discharges", Proceedings of the IEE, Vol. 98, Pt. I, pp. 4459,1951

[16] J. H. Mason, "Breakdown of insulation by discharges", Proceedings of the IEE, Vol. 100, Pt. IIA, pp. 149-158, 1953

[17] W. Boenig, "Luftgehalt und Luftspaltverteilung geschichteter Dielektrika", Archiv fuer Elektrotechnik, Vol. 48, pp. 85-96, 1963

[18] A. Kelen, M. G. Danikas, "Evidence and presumption in PD diagnostics", IEEE Transactions on Dielectrics and Electrical Insulation, Vol. 2, No. 5, pp. 780-795, 1995

[19] J. H. Mason, "Breakdown of solid dielectrics in divergent fields", Proceedings of the IEE, Vol. 102, Pt. C, pp. 254-263, 1955

[20] J. H. Mason, "Discharges", IEEE Transactions on Electrical Insulation, Vol. 13, No. 4, pp. 211-238, 1978

[21] E. Friedlander, J. R. Reed, "Electrical discharges in air gaps facing solid insulation in high-voltage equipment", Proceedings of the IEE, Vol. 100, Pt. IIA, pp. 121-131, 1953

[22] S. I. Reynolds, "On the behavior of natural and artificial voids in insulation under internal discharge", AIEE Transactions on Power Apparatus and Systems, Vol. PAS-77, Pt. III, pp. 1604-1608, 1959

[23] M. S. Naidu, V. Kamaraju, High voltage engineering, Tata McGrawHill, New Delhi, India, 2000

[24] E. C. Rogers, "The self-extinction of gaseous discharges in cavities in dielectrics", Proceedings of the IEE, Vol. 105A, pp. 621-630, 1958

[25] A. A. Hossam-Eldin, S. S. Dessouky, S. M. El_Mekkaway, R. A. Abd El-Aal, "Internal discharges in cavities in solid dielectric materials", Journal of Electrical Engineering, Vol. 9, No. 4, Art. No. 13, 2009

[26] R. J. Meats, A. W. Stannett, "Degradation of insulation materials by electrical discharges", IEEE Transactions on Power, Apparatus and Systems, Vol. PAS- 83, pp. 49-54, 1964

[27] R. Bartnikas, G. L. d' Ombrain, "A study of corona discharge rate and energy loss in spark gaps", IEEE Transactions on Power, Apparatus and Systems, Vol. PAS-84, No. 9, pp. 770-778, 1965

[28] I. Y. Megahed, B. C. Mansfield, R. E. Wootton, "Detection and measurement of discharges in cavities in solid dielectrics", Proceedings of the IEE, Vol. 114, No. 11, pp. 1822-1824, 1967

[29] I. Y. Megahed, "The discharge-repetition rate in cavities in epoxy resin, polyethylene, and mica under alternating voltage conditions", IEEE Transactions on Electrical Insulation, Vol. 10, No. 2, pp. 69-74, 1975

[30] T. Tanaka, Y. Ikeda, "Internal discharges in polyethylene with an artificial cavity", IEEE Transactions on Power, Apparatus and Systems, Vol. PAS-90, No. 4-6, pp. 2692-2702, 1971

[31] R. J. Densley, B. Salvage, "Partial discharges in gaseous cavities in solid dielectrics under impulse voltage conditions", IEEE Transactions on Electrical Insulation, Vol. 6, No. 2, pp. 54-62, 1971 
[32] H. Okamoto, M. Kanazashi, T. Tanaka, "Deterioration of insulating materials by internal discharge", IEEE Transactions on Power, Apparatus and Systems, Vol. PAS-96, No. 1, pp. 166-177, 1977

[33] T. Tanaka, A. Greenwood, Advanced power cable technology: basic Concepts and testing, CRC Press, USA, 1983

[34] T. Tanaka, A. Greenwood, Advanced power cable technology: present and future, CRC Press, USA, 1983

[35] S. J. Rigby, B. M. Weedy, "Partial discharges in liquid-nitrogen impregnated taped-cable insulation", Proceedings of the IEE, Vol. 123, No. 2, pp. 165-170, 1976

[36] K. Horii, A. J. Pearmain, A. J. McNerney, "Correlation of electrical breakdown of supercritical helium in short gaps with partial discharge in cable samples", Crygenics, Vol. 23, No. 2, pp. 102-106, 1983

[37] P. N. Nikolopoulos, D. N. Diamantopoulos, "Behavior of pressboard-oil insulation under alternating voltages of industrial frequency in a nonuniform electric field", Proceedings of the IEE, Vol. 130, Pt. A, No. 3, pp. $145-151,1983$

[38] S. Selvakumar, R. S. Nema, "Low pressure discharges in narrow cylindrical voids", 3rd IEE International Conference on Dielectrics Materials, Measurements and Applications, United Kingdom, September 10-13, 1979

[39] A. C. Gjaerde, Multi-factor ageing of epoxy: the combined effect of temperature and partial discharges, Ph.D. Thesis, Norwegian University of Science and Technology, Faculty of Electrical Engineering and Computer Science, Department of Power Engineering, 1994

[40] B. Stenerhag, A. Danemar, "Partial discharge characteristics of some liquid impregnated system", 3rd IEE International Conference on Dielectrics Materials, Measurements and Applications, United Kingdom, September 10-13, 1979

[41] J. P. Reynders, "Electrical detection of degradation caused by partial discharges in polythene", IEE International Conference on Dielectric Materials, Measurements and Applications, United Kingdom, July 2125, 1975

[42] J. P. Reynders, "Measurement of the effects of partial discharge activity on low density polyethylene", 3rd IEE International Conference on Dielectrics Materials, Measurements and Applications, United Kingdom, September 10-13, 1979

[43] R. R. Opoku, E. G. Robles, J. H. Mason, "Degradation and breakdown of polypropylene film by internal discharges", IEE International Conference on Dielectric Materials, Measurements and Applications, United Kingdom, July 21-25, 1975

[44] J. H. Mason, "Enhancing the significance of PD measurements", IEEE Transactions on Dielectrics and Electrical Insulation, Vol. 2, No. 5, pp. 876-888, 1995

[45] K. D. Wolter, J. Tanaka, J. F. Johnson, "A study of gaseous degradation products of corona-exposed polyethylene", IEEE Transactions on Electrical Insulation, Vol. 17, No. 3, pp. 248-252, 1982

[46] J. Golinski, J. H. Calderwood, S. Zoledziowski, A. Sierota, "Partial discharges in a cylindrical void with a metal rod electrode", IEEE Transactions on Electrical Insulation, Vol. 17, No. 6, pp. 560-569, 1982

[47] G. Garcia, B. Fallou, "Equipment for the energy measurement of partial discharges", 1st International Conference on Conduction and Breakdown in Solid Dielectrcs, France, July 4-8, 1983

[48] F. Viale, J. Poitevin, B. Fallou, J. F. Morel, R. Buccianti, S. Yakov, S. Cesari, E. Serena, "Study of a correlation between energy of partial discharges and degradation of paper-oil insulation", CIGRE, Report 1512 , pp. $1-9,1982$

[49] A. R. Nosseir, M. M. A. Salama, A. Soliman, M. Rizk, "Discharge detection and measurement in voids in solid dielectrics", 1984 IEEE International Symposium on Electrical Insulation, Canada, June 11-13, 1984

[50] M. G. Danikas, A study of the behavior of a uniaxially orientated polyethylene tape/oil insulating system subjected to electrical and thermal stresses, Ph.D. Thesis, University of London, Queen Mary College, Department of Electrical and Electronic Engineering, 1985

[51] A. J. Pearmain, M. G. Danikas, "A study of the behavior of a uniaxially oriented polyethylene/oil insulating system subjected to electrical and thermal stresses", IEEE Transactions on Electrical Insulation, Vol. 22, No. 4, pp. 373-382, 1987

[52] R. Liao, J. Yan, L. Yang, M. Zhu, B. Liu, "Study of the relationship between damage of oil-impregnated insulation paper and evolution of phase-resolved partial discharge patterns", European Transactions on Electrical Power, Vol. 21, pp. 2112-2124, 2011

[53] T. Tanmaneeprasert, P. L. Lewin, "The use of partial discharge analysis for the diagnosis of electrical ageing in polymeric insulation containing cavities", Electrical Insulation Conference, Canada, June 19-22, 2016

[54] K. Theodosiou, D. P. Agoris, I. Gialas, I. Vitellas, "Measurements of partial discharges and power losses in PET films in high voltage AC fields", Journal of Electrical Engineering, Vol. 58, No. 5, pp. 250-256, 2007

[55] M. G. Danikas, "Some possible new applications of a partial discharge (PD) model and its relation to PD detection sensitivity", European Transactions on Electrical Power, Vol. 6, No. 6, pp. 445-448, 1996

[56] M. G. Danikas, G. E. Vassiliadis, "Models of partial discharges (PD) in enclosed cavities in solid dielectrics: A study of the relationship of PD magnitudes to the sensitivity of PD detectors and some further comments on insulation lifetime", Journal of Electrical Engineering, Vol. 54, No. 5-6, pp. 132-135, 2003

[57] A. A. Hossam-Eldin, "Analysis of discharge damage and breakdown in gaseous Cavities in insulating materials", Journal of Physics D: Applied Physics, Vol. 17, pp. 421-428, 1984

[58] E. Jahoda, J. Kudelcik, "Internal partial discharge in cavity of polyurethane", Procedia Engineering, Vol. 192, pp. 365-369, 2017

[59] T. Tanmaneeprasert, P. L. Lewin, "Electrical treeing and ageing characteristics in cavities of low density polyethylene dielectrics on partial discharge measurements", IEEE Conference on Electrical Insulation and Dielectric Phenomena, Canada, October 16-19, 2016

[60] T. Tanaka, T. Okamoto, K. Nakanishi, T. Miyamoto, "Aging and related Phenomena in modern electric power systems", IEEE Transactions on Electrical Insulation, Vol. 28, No. 5, pp. 826-844, 1993

[61] J. C. Devins, "The physics of partial discharges in solid dielectrics", IEEE Transactions on Electrical Insulation, Vol. 19, No. 5, pp. 475-495, 1984

[62] J. P. Habas, J. M. Arrouy, F. Perrot, "Effects of electric partial discharges on the rheological and chemical properties of polymers used in HV composite insulators after railway service", IEEE Transactions on Dielectrics and Electrical Insulation, Vol. 16, No. 5, pp. 1444-1454, 2009

[63] M. Kannan, P. Sreejaya, "Partial discharge detection in solid dielectrics", International Journal of Scientific and Engineering Research, Vol. 4, No. 8, 2013

[64] Z. Lei, J. Song, M. Tian, X. Cui, C. Li, M. Wen, "Partial discharges in cavities in ethylene propylene rubber", IEEE Transactions on Dielectrics and Electrical Insulation, Vol. 21, No. 4, pp. 1647-1659, 2014

[65] I. Kolcunova, M. Sipos, "Measurement of partial discharge in discshaped voids", 8th International Scientific Symposium on Electrical Power Engineering (Elektroenergetika 2015), Slovakia, September 1618,2015

[66] M. G. Danikas, A. Kelen, "Diagnostic PD pulse techniques: a discussion on possibilities and limitations", Nordic Insulation Symposium, Norway, June 10-12, 1996

[67] D. P. Agoris, N. D. Hatziargyriou, "Two voids model for simulation of partial discharges in solid dielectrics", Modelling, Simulation \& Control, Vol. 42, No. 2, pp. 1-14, 1992

[68] M. G. Danikas, "Partial discharge behavior of two (or more) adjacent cavities in polyethylene samples", Journal of Electrical Engineering, Vol. 52, No. 01-02, pp. 36-39, 2001

[69] D. P. Agoris, N. D. Hatziargyriou, "Approach to partial discharges development in closely coupled cavities embedded in solid dielectrics by the lumped capacitance model", IEE Proceedings-A, Vol. 140, No. 2, pp. 131-134, 1993

[70] D. P. Agoris, N. D. Hatziargyriou, "A modelistic consideration of the interaction between discharges in cavities of solid dielectrics", 8th 
International Symposium on High Voltage Engineering, Japan, August 23-27, 1993

[71] D. P. Agoris, N. D. Hatziargyriou, "Application of the EMTP program in the study of discharges in two cavities enclosed in a solid dielectric during its stressing with AC or impulse voltage", CIGRE Greek National Committee, Greece, February 10-11, 1994 (in Greek)

[72] A. M. Bruning, D. G. Kasture, F. J. Campbell, N. H. Turner, "Effect of cavity sub-corona current on polymer insulation life", IEEE Transactions on Electrical Insulation, Vol. 26, No. 4, pp. 826-836, 1991

[73] M. G. Danikas, "On the damage of insulating materials below inception voltage", Journal of Electrical Engineering, Vol. 52, No. 11-12, pp. 367371,2001

[74] A. Harlin, M. G. Danikas, P. Hyvonen, "Polyolefin insulation degradation in electrical field below critical inception voltages", Journal of Electrical Engineering, Vol. 56, No. 5-6, pp. 135-140, 2005

[75] Y. Zhang, M. G. Danikas, X. Zhao, Y. Cheng, "Preliminary experimental work on nanocomposite polymers: Small partial discharges at inception voltage, the existence of possible charging mechanisms below inception voltage and the problem of definitions", Journal of Electrical Engineering, Vol. 63, No. 2, pp. 109-114, 2012

[76] Y. Zhang, M. G. Danikas, X. Zhao, Y. Cheng, "Charging phenomena below the inception voltage: Effects of nanofillers on epoxy", Malaysian Polymer Journal, Vol. 7, No. 2, pp. 68-73, 2012

[77] Y. Shibuya, S. Zoledziowski, J. H. Calderwood, "Void formation and electrical breakdown in epoxy resin", IEEE Transactions on Power, Apparatus and Systems, Vol. 96, pp. 196-206, 1977

[78] T. Tanaka, "Internal partial discharge and material degradation", IEEE Transactions on Electrical Insulation, Vol. EI-21, No. 6, pp. 899-905, 1986

[79] R. Bartnikas, J. P. Novak, "On the character of different forms of partial discharge and their related terminologies", IEEE Transactions on Electrical Insulation, Vol. 28, No. 6, pp. 956-968, 1993

[80] C. Hudon, R. Bartnikas, M. R. Wertheimer, "Chemical and physical degradation effects on epoxy surfaces exposed to partial discharges", 4th International Conference on Properties and Applications of Dielectric Materials, Australia, July 3-8, 1994

[81] P. H. F. Morshuis, "Assessment of dielectric degradation by ultrawideband PD Detection", IEEE Transactions on Dielectrics and Electrical Insualtion, Vol. 2, No. 5, pp. 744-760, 1995

[82] M. G. Danikas, "Small partial discharges and their role in insulation deterioration", IEEE Transactions on Dielectrics and Electrical Insulation, Vol. 4, No. 6, pp. 863-867, 1997

[83] J. Sletbak, "Partial discharge measurements: possibilities and limitations", 4th International Conference on Conduction and Breakdown in Solid Dielectrics, Italy, June 22-25, 1992

[84] M. G. Danikas, "Some new relationships and a scaling law regarding partial discharges in spherical cavities enclosed in solid insulation", Acta Electrotehnica Napocensis, Vol. 39, No. 1, pp. 5-9, 1998

[85] R. E. James, B. T. Phung, "Development of computer-based measurements and their applications to PD pattern analysis", IEEE Transactions on Dielectrics and Electrical Insulation, Vol. 2, No. 5, pp. 838-856, 1995

[86] M. G. Danikas, N. Gao, M. Aro, "Partial discharge recognition using neural networks: A review", Archiv fuer Elektrotechnik (Electrical Engineering), Vol. 85, pp. 87-93, 2003

[87] G. C. Stone, "A perspective on online partial discharge monitoring for assessment of the condition of rotating machine stator winding insulation”, IEEE Electrical Insulation Magazine, Vol. 28, No. 5, pp. 813,2012

[88] M. Wu, H. Cao, J. Cao, H. L. Nguyen, J. B. Gomes, S. P. Krishnaswamy, "An overview of state-of-the-art partial discharge analysis techniques for condition monitoring", IEEE Electrical Insulation Magazine, Vol. 31, No. 6, pp. 22-35, 2015

[89] D. Moraru, C. Popesco, M. Stoica, F. Tanasesco, "Detection of degradation produced by partial discharges in paper-oil insulation", CIGRE Report, Paper 15-05, pp. 1-8, 1970
[90] H. Gsodam, "Investigations of the energy of internal partial discharges by AC stress", 4th International Symposium on High Voltage Engineering, Athens, Greece, September 5-9, 1983

[91] O. Shutenko, "Faults diagnostics of high-voltage equipment based on the analysis of the dynamics of changing of the content of gases", Energetika, Vol. 64, No. 1, pp. 11-22, 2018

[92] M. Duval, “A review of faults detectable by gas-in-oil analysis in transfmormers", IEEE Electrical Insulation Magazine, Vol. 18, No. 3, pp. $8-17,2002$

[93] M. Duval, "New techniques for dissolved gas-in-oil analysis", IEEE Electrical Insulation Magazine, Vol. 19, No. 2, pp. 6-15, 2003

[94] K. Sahitya Yadav, Understanding the impact of thermal ageing on dielectric properties of transformer insulation, Ph.D. Thesis, Indian Institute of Technology, Department of Electrical Engineering, Chennai, India, 2017

[95] G. Mole, "Improved methods of test for the insulation of electrical equipment", Proceedings of the IEE, Vol. 100 (IIA), pp. 276-283, 1953 